\title{
A Preliminary Report on a Therapeutic Trial with Acedapsone in Lepromatous Leprosy*
}

\author{
K. RAMANUJAM, C. G. S. IYER AND G. RAMU \\ Central Leprosy Institute, \\ P.O. Tirumani, Chingleput 603001, S. India
}

\begin{abstract}
Fifty cases of lepromatous leprosy were included in a double blind trial to assess the therapeutic value of DADDS in lepromatous leprosy using DDS as the control drug. During the period of 19 months the study has been in progress, 28 cases were lost to the study owing to patients going away on voluntary discharge, etc. In the 22 cases who continued to participate in the study over a period of 15-19 months, the findings indicate that the drug is effective and well tolerated.
\end{abstract}

\section{Subjects for the Study}

Young male adults suffering from moderate to well advanced uncomplicated active lepromatous leprosy confirmed histopathologically and immunologically constituted subjects for the study. Although it was originally intended that only those cases with Morphological Index of at least $4 \%$ and above should be included in the study, this criterion had to be relaxed because of the non-availability of such subjects.

\section{Size and Duration}

A total of 50 cases were included in the study. They were allocated to one or other of the 2 groups, the Trial Group and Control Group, by randomization. The duration of the trial was initially fixed for two years, its further continuance being determined by the observations made during this period.

\section{Methods}

The Trial Group received DADDS in a dose of $225 \mathrm{mg}$ by the intramuscular route once in 75 days, and placebo tablets every day. The Control Group received

* This investigation received financial support from the WHO. 
placebo injection once in 75 days, and tablets of DDS orally every day in strict relation to body weight, starting with a small dose, stepping up gradually and reaching the maximum dose of $10 \mathrm{mg} / \mathrm{kg}$ body weight/week over a period of 22 weeks as per the schedule given by the WHO.

\section{Investigations}

Initially the patients were given a complete physical examination to exclude serious intercurrent disease. Subsequently investigations including recording of leprosy status of the patient, bacteriological examination, haemogram, liver function tests, urinalysis and stools examination, skin biopsy for histopathological examination, lepromin test using lepromin supplied by the WHO Regional Reference Centre, clinical photography, and recording of body weight, were carried out.

During the follow-up, clinical charting of the cases, bacteriological examination, liver function tests, haemogram, urinalysis and stools examination were repeated every 3 months. Body weight was recorded every month. Skin biopsy was repeated once a year or earlier if found necessary. Clinical photography was repeated as and when indicated. Sulphone level in the blood and urinary excretory pattern of the drug were carried out prior to the injection of the drug, 4 days, 6 dave, 25 days, and 50 days following the injection of DADDS using the fluorimetric method of Glazko et al.

\section{The Study Proper}

The investigation commenced on 1 February, 1973 with 19 cases and during the intake phase, lasting 5 months, 31 more cases were added to the study bringing the total to 50, 25 in the Trial Group and 25 in the Control Group. During the course of 19 months the investigation has been in progress, 28 cases were lost to the study due to various reasons. As on 31 August, 1974 there are 22 cases participating in the investigation. Fifteen of these cases are on DADDS and 7 receiveDDS orally.

The 15 subjects in the Trial Group have received 6 to 8 injections of $225 \mathrm{mg}$ of the drug intramuscularly each time at an interval of 75 days and placebo tablets orally every day. Cases in the Control group numbering 7, have been on continuous DDS therapy by the oral route and have received 6 to 8 injections of placebo intramuscularly once in 75 days.

\section{Findings}

(i) All the cases, both on DADDS and DDS have recorded progressive clinical improvement, (ii) only 1 case receiving DADDS has shown improvement bacteriologically, (iii) regarding the occurrence of complications 2 cases in the Trial Group developed severe lepra reaction, one of which has become recurrent and another pustular. A third case manifested painful arthritis of the knees and 3 had 1-2 attacks of lepra reaction. In the control group, 3 cases developed recurrent attacks of lepra reaction and 2 others lepra reaction twice, (iv) DADDS is well-tolerated, though causing some pain at the injection site for 24 to $48 \mathrm{~h}$ following the injection, and (v) laboratory investigations revealed normal values throughout in all the cases. 
In conclusion it may be said that the present findings indicate that DADDS is well tolerated, and appears to be effective. Further, though there are no indications so far regarding the development of drug resistance with this treatment, this probability should be borne in mind. 